\title{
Cambio tecnológico en la metalurgia de las Baleares (Calcolítico y Edad del Bronce) (1)
}

\author{
Changement tecnologique dans la métallurgie des Iles Baleares \\ (Chalcolitique et Age du Bronze)
}

Bartomeu Salvà Simonet $(*)$

\section{RESUMEN}

En el presente trabajo se dan a conocer las características más importantes de las primeras etapas de la metalurgia prehistórica balear (Calcolítico y Edad del Bronce). Se distinguen dos tecnologías que responden no sólo a formas de trabajar el metal, sino también de entenderlo y usarlo. Este estudio se apoya en datos procedentes de 400 análisis de composición y 14 metalografías.

\section{RESUMÉE}

Dans le travail suivant en va faire connaitre les traits les plus importants des pprémierès ages de la métallurgie prehistorique baléar (Calcolitiques et Âge de Bronze). O établit une division entre deux moments tecnologiquement différents qui ne répondent pas seulement à façons du travailler le métal, mais aussi de le comprendre et l'utiliser. Tot ça (accompagne avec donnés provénantes de plus de 400 analyses de composition et diferentes métallographies.

Palabras clave: Arqueometalurgia; Baleares; Naviforme; Composición; Metalografía; Bronce; Arsénico.

Paroles clef: Arqueometallurgie; Illes Balears; Naviforme; Composition; Metallographie; Bronze; Arsénic.

(*) Profesor Asociado de Prehistoria de la Universitat de les Illes Balears. C/ Valldemossa, Km. 7,5. Palma, Balears. Correo electrónico: tomeusal@hotmail.com

Recibido: 12-II-2010; aceptado: 8-V-2010.

(1) Este artículo es parte de la transferencia de conocimiento del proyecto de investigación $\mathrm{I}+\mathrm{D}$ financiado por el Ministerio de Ciencia y Tecnología (HAR2008-00708): Producir, consumir, intercambiar. Explotación de recursos y relaciones externas de las comunidades insulares baleáricas durante la prehistoria reciente.

\section{INTRODUCCIÓN}

Hasta el momento la metalurgia prehistórica de las islas Baleares (Fig. 1) sólo se ha estudiado desde la tipología (Rosselló 1975; 1987; Gual 1993) o de forma parcial (Delibes y Fernández-Miranda 1988; Rovira 1988; 2003; Rovira et al. 1991; Montero et al. 2005; Salvà y Calvo 2007). El presente estudio, en cambio, adopta una visión integradora de todos los aspectos relacionados con este tema.

Los datos de este trabajo se apoyan en 401 análisis de composición y 14 metalografías. Para las primeras se ha utilizado un microscopio electrónico de barrido (MEB), Hitachi S-530 con un sistema acoplado de microanálisis R-X-EDS "Link-Isis" que forma parte de los Servicios científico-técnicos de la Universidad de las Islas Baleares. Para las metalografías, además, se ha utilizado uno óptico marca Olympus.

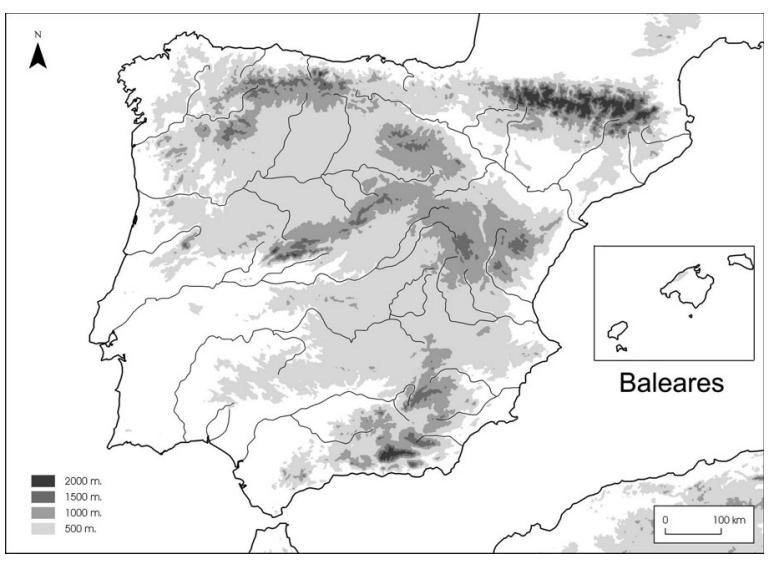

Fig. 1. Localización general de las Islas Baleares. 
El análisis elemental realizado con MEB no permite detectar elementos traza. Los análisis realizados en Madrid por el Dr. Salvador Rovira con un espectrómetro de fluorescencia de rayos X (ED-XRF), Kevex, modelo 7000, si permitieron obtener información sobre la presencia de elementos minoritarios en el metal (Rovira et al. 1997: 6-7).

En primer lugar, cabe destacar que se ha constatado claramente una división de la técnica metalúrgica en dos etapas:

1. Primer Período: Calcolítico y Naviforme I (2200-1400 a.C.). Calcolítico y Bronce Antiguo.

2. Segundo Período: Naviforme II y III (1400-850 a.C.). Bronce Reciente.

\section{TRANSFORMACIÓN Y PRODUCCIÓN}

El origen del cobre utilizado en las Baleares, es un aspecto aún no resuelto. Las últimas investigaciones reflejan que al menos parte del metal podría ser autóctono (Perelló, 2010; Lull et al. e.p.; Salvà et al. e.p.). Pero no se puede obviar que una cantidad significativa de objetos prehistóricos se fabricaron sobre cobre arsenicado, y hasta el momento no se ha detectado minerales con esas características en las islas. También se han encontrado evidencias de los procesos de transformación y producción, que se basan en la tecnología de la vasija de reducción, y que no parece cambiar a lo largo de los períodos estudiados. Estas vasijas se documentan por primera vez en Son Matge (Valldemossa, Mallorca), a finales del Calcolítico (2100 a.C.) y siguen en uso en los momentos más modernos de Son Mercer de Baix (Ferreries, Menorca) (1400/1300 a.C.). Posiblemente este método no cambió hasta los últimos momentos del Bronce Final o incluso hasta la plena Edad del Hierro.

Se han hallado vasijas de reducción en Son Matge, es Vel·lar (Santanyí, Mallorca), es Closos de Can Gaià (Felanitx, Mallorca), Cala Blanca (Ciutadella, Menorca), Son Ferrandell Olesa (Valldemossa, Mallorca) y Son Mercer de Baix. Algunos de los fragmentos de cerámica documentados posiblemente sean crisoles, aunque sólo los análisis podrán confirmarlo.

Por tanto, en las Baleares se constata claramente una tecnología común, en las mismas cronologías que en la Península Ibérica y el Sur de Francia, desde donde seguramente fue importada a finales del Calcolítico. Por ese motivo las $\mathrm{Ba}-$ leares serían uno de los últimos lugares a donde este sistema de trabajo metalúrgico se expandió.

\section{METALES Y ALEACIONES}

Si se observa la figura 2, se puede comprobar que el cobre sin alear es mayoritario en el primer período (53\%) y se reduce considerablemente en el segundo (24\%). Analizando este proceso con mayor profundidad se puede intuir que algunos yacimientos (Fig. 3), ya sea por su mayor antigüedad (Sa Canova d'Ariany, Mallorca), o bien por su largo uso con unos inicios muy arcaicos (Can Martorellet, Pollença, Mallorca; Can Maiol, Palma, Mallorca) tienen más objetos de cobre. Difícilmente se pueden inferir conclusiones definitivas de este gráfico, pero sirve para constatar que el cobre sin alear es mayoritario durante el Calcolítico y Naviforme I, y conforme avanzamos en el tiempo irá reduciendo su presencia a favor de la aleación de bronce ( $\mathrm{Na}$ Fonda, ses $\mathrm{Sa}-$ lines, Mallorca; Cometa des Morts, Escorca, Mallorca; Solleric, Alaró, Mallorca).

Los primeros objetos de bronce que se han podido datar son los punzones de s'Aigua Dolça (Artà, Mallorca), con una cronología de $3460 \pm 40$ BP (UTC-4744) cuyo rango cronológico a dos sigmas una vez calibrado sería de 1894-1667 cal. a.C. (Guerrero et al., 2003). Si consideramos el rango de mayor probabilidad podríamos acotar la cronología al período

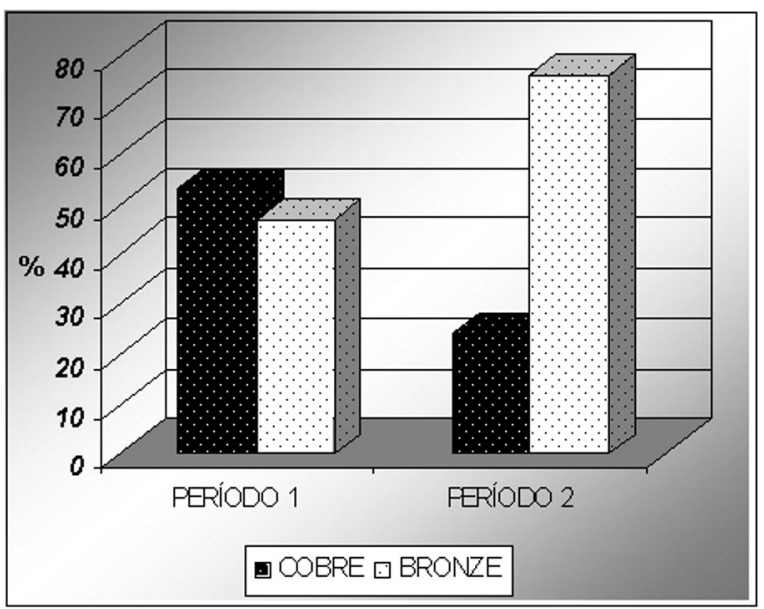

Fig. 2. Cuantificación del cobre y bronce por período en frecuencias absolutas. 


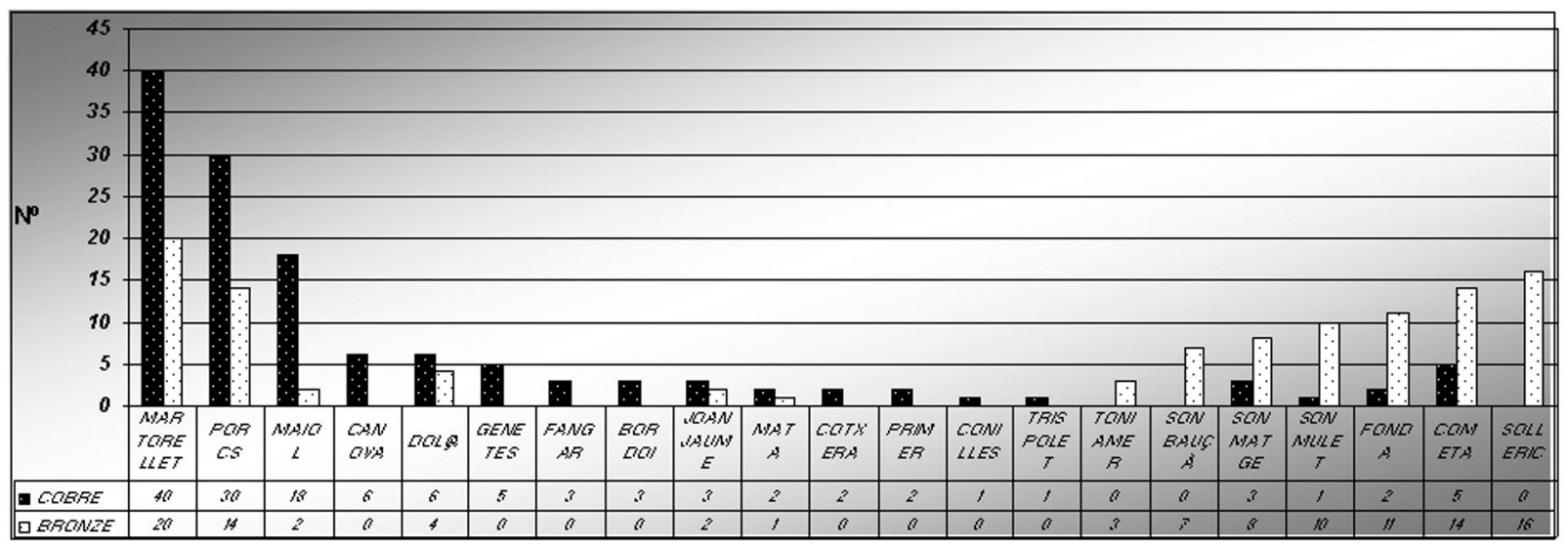

Fig. 3. Cuantificación del cobre y bronce por yacimientos del 1. ${ }^{\mathrm{er}}$ período en frecuencias absolutas.

1847-1714 cal. a.C. Ello podría evidenciar una llegada tardía de esta aleación en Mallorca, sobre todo si se compara con las fechas de la Bauma del Serrat del Pont (Alta Garrotxa, Tarragona) que se sitúan entre el 2800 y el 2450 cal. a.C. (Alcalde et al., 1998). Aun así, no puede descartarse una cronología anterior del uso del bronce en las Baleares ya que existen algunos punzones en Son Matge y Coval den Pep Rave, sin contexto claro, que podrían ser del Calcolítico.

Del estudio de la cantidad de estaño presente en las piezas de bronce y de la comparación entre las dos fases, se pueden inferir algunos datos relevantes (Fig. 4). La frecuencia de objetos en los intervalos de contenido de estaño tienden a una distribución normal, en la que los valores de los extremos $(0-5 \%$ y $>15 \%)$ son inferiores a las frecuencias de los grupos centrales $(5-10 \%$, $10-15 \%)$. Esta misma tendencia es la única similitud entre las dos fases estudiadas, ya que en el Calcolítico y Naviforme I hay un mayor número de objetos con aleaciones pobres de estaño (0-5\%). El contenido medio de estaño se incrementa: en el primer período es del $8,9 \%$ y en el segundo pasa al 10,96\%. Parece evidente que en el segundo período las piezas de bronce incluyen más estaño, pero no queda claro si este es un proceso controlado. La variabilidad en el porcentaje de estaño aleado es grande, especialmente en el primer período. Un ejemplo lo encontramos en el yacimiento de Sa Cometa des Morts, en donde un punzón presenta $19,1 \%$ de estaño y otro sólo el 10,4\%. Otras evidencias aún más claras, se dan en Na Fonda. En este hipogeo se encontró un punzón con un $19,8 \%$ de estaño y otro con el $8,96 \%$. En la cueva natural de Can Martorellet un punzón es un bronce rico (19,2 \%) y otro sólo apenas contiene el $2,2 \%$. Esta variación en la composición de un mismo tipo de objeto se detecta también en Solleric, Son Maiol y otros yacimientos.

Probablemente estos casos demuestran el conocimiento de la aleación, pero con una falta de control en las proporciones $y$, por tanto, estaríamos en una fase de pruebas y tanteos. En estos momentos en las Isalas Baleares posiblemente existirían unos trabajos autóctonos en los que no hay una adición estandarizada del Sn. Por este motivo, algunos punzones presentan valores de estaño de casi un $20 \%$ y otros ni siquiera llegan al $3 \%$. En otros estudios anteriores, se ha documentado que la aleación de cobre y estaño durante el Bronce Antiguo y Medio se encuentra en

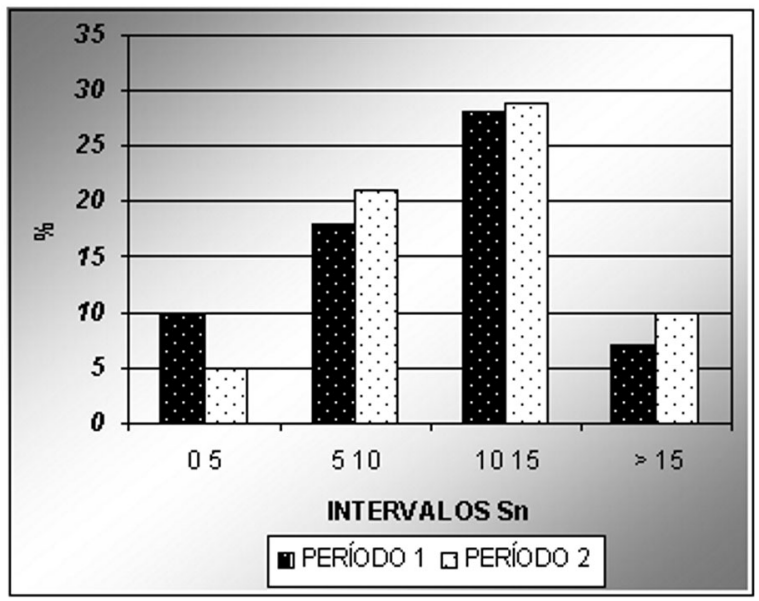

Fig. 4. Comparación de los intervalos de Sn por período en frecuencias absolutas. 


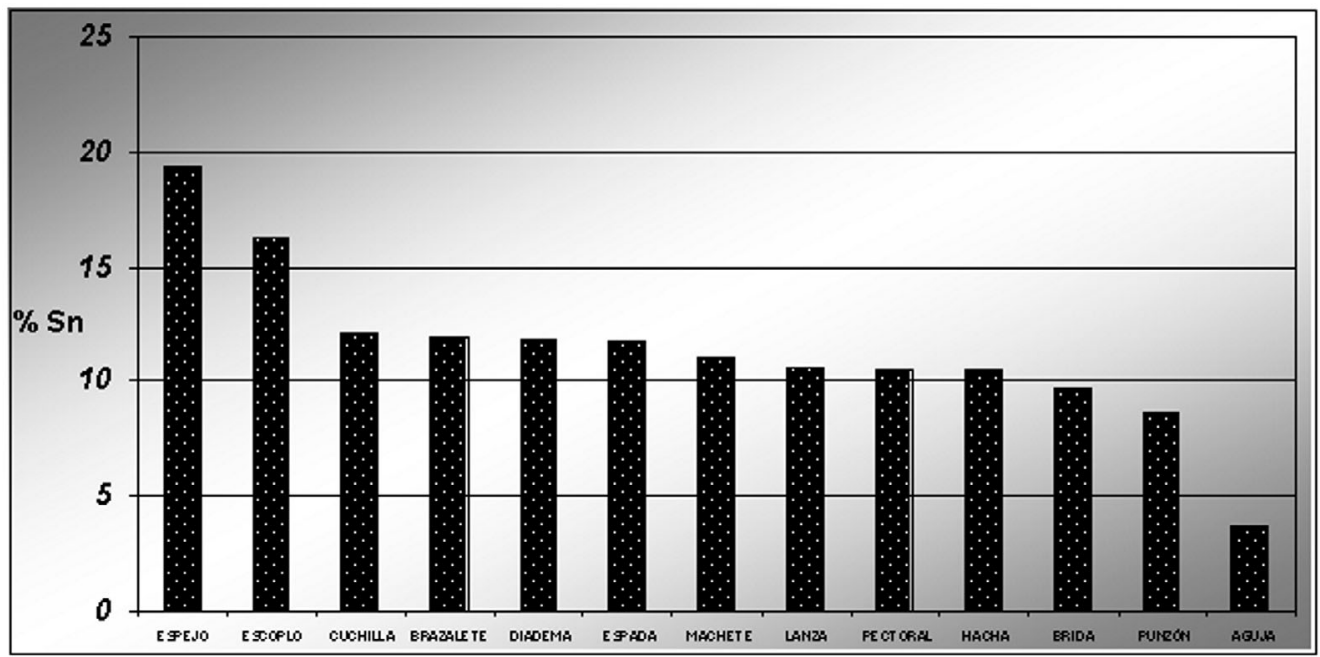

Fig. 5. Media de Sn por familias del $2 .^{\circ}$ período en $\%$ en peso.

una fase de pruebas y tanteos que se detecta con saltos constantes en los porcentajes de estaño (Rovira 2004: 26; Rodríguez 2005: 169). Aún así no se debe olvidar que en estas cronologías el estaño seguirá conviviendo con el cobre sin alear (Rovira 2004: 25).

Todo lo comentado anteriormente parece sufrir un cambio relevante en el segundo período. Las piezas de bronce incluyen una mayor cantidad de estaño, además de una cierta estandarización, sobre todo si se computan las piezas por familias (Fig. 5). Las medias de estaño se sitúan entre el 10 y el $12 \%$, valores que presentan una relación óptima entre dureza y fragilidad. El mayor contenido en estaño de los escoplos y los espejos y el menor en las agujas podría deberse a cuestiones de uso de esos objetos.

También se han detectado dos elementos mayoritarios, aunque siempre en porcentajes mucho menores que el estaño y que varían su comportamiento según la etapa estudiada. En el primer momento destaca el arsénico y en el segundo el plomo.

El arsénico está presente en un $23,4 \%$ de las piezas analizadas. Los cuchillos son claramente los objetos en los cuales hay mayor presencia de arsénico $(66,6 \%)$ y también mayor porcentaje. Así el valor medio de arsénico en punzones es del $2,09 \%$ frente al 5,56 \% de los cuchillos. En el segundo período en cambio, el arsénico nunca pasa del $1 \%$, con una media del $0,41 \%$ y por tanto deja de ser un elemento mayoritario.
El motivo de la importancia del arsénico en el primer período aún no puede concretarse. Sin embargo, las vetas de cobre hasta ahora analizadas en las Baleares no presentan casi arsénico, lo que obliga a pensar en un origen fuera de las islas. El problema estriba en si el metal de cobre con arsénico llega a las Baleares como materia prima, a partir de la cual se fabrican las piezas o, por el contrario, como objetos producidos en otros lugares y posteriormente importados hasta las islas.

Si realmente existió un aprovisionamiento externo de mineral, lo más lógico sería pensar que éste se pudo utilizar igualmente para fabricar todo tipo de piezas. Pero en el registro arqueológico balear, el arsénico está presente casi de forma exclusiva en los cuchillos. Este fenómeno es aún más evidente si se contabiliza la cantidad de arsénico presente en esta familia tipológica, superando en ocasiones valores del $8 \%$ As.

Seguramente el mayor contenido de arsénico que en otras piezas debe relacionarse con su uso y con las implicaciones técnicas que, voluntariamente o no, tuvieron estas aplicaciones (2). Posiblemente los cuchillos de las Baleares serían,

(2) En este trabajo no se trata de dilucidar si el arsénico fue o no un componente añadido de forma voluntaria con la intención de crear un bronce arsenicado artificial (Delibes et al., 1989; 1991) (Rovira, 2004: 17), o si los cuchillos serían unos objetos fabricados intencionalmente con materia prima de vetas compuestas de cobre y arsénico (Rovira, 2004: 17-19) temas ampliamente tratados y aclarados por diversos autores. De hecho estas problemáticas se refieren a contextos, en que ha diferencia de las Baleares, si existen vetas de cobre arsenicado. 
como en otros lugares, unas piezas con un significado muy relevante, motivo por el que casi no se reciclaron y al terminar su vida se amortizaron en las tumbas. Al no ser piezas refundidas, el metal no sufrió perdida de arsénico, detectándose los porcentajes originales elevados (Rovira 2004: 25).

Otra explicación, compatible con la anterior sería que los cuchillos además de no reciclarse, también serían unos objetos que por su preeminencia no se pudiesen fabricar con metal autóctono. En estos casos se importaría el mineral o las piezas ya acabadas. En estos momentos lo único que parece cierto, es que el mineral con el que se hacen tales piezas no sería local.

El arsénico en el segundo período estudiado se difumina con porcentajes casi siempre inferiores al $0,5 \%$, e incluso en algunas ocasiones apenas es detectable. Posiblemente los metales que se importan del exterior, como objetos o como lingotes, ya no conservan este componente. Ello podría señalar hacia una nueva capacidad de elevar las temperaturas de los hornos y por tanto de que el arsénico se volatilice (Rovira 2004: 19). Seguramente el reciclaje también aumentó en este período.

Otro aspecto que también diferencia ambas etapas es el modelo de impurezas del metal. En la figura 6 se puede comprobar como los valores medios de la mayoría de los elementos de las dos épocas no varían demasiado. Esto se cumple especialmente en lo que respecta al hierro, la plata,

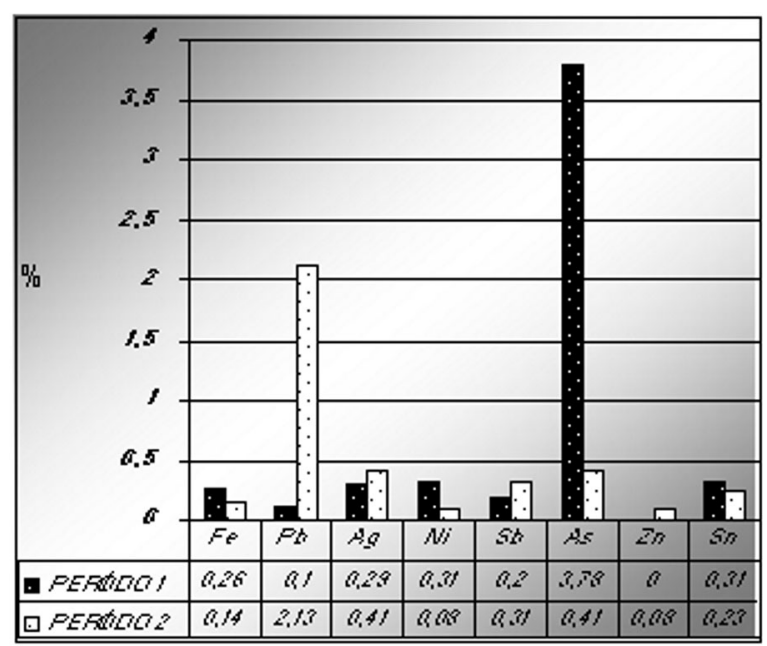

Fig. 6. Medias de elementos minoritarios por período en $\%$ en peso. el níquel, el antimonio, el zinc y el estaño; todos ellos por debajo del $0,5 \%$.

En el segundo período cabe destacar como nuevo elemento el plomo, que en ocasiones se presenta como un simple elemento minoritario, pero con valores mayoritarios en otras. Aun así los porcentajes de plomo no son excesivamente altos. Sólo en una ocasión alcanza el $7 \%$ en una de las hachas de Can Gallet (Formentera), pero en general los valores de plomo son mucho más bajos. Esta hacha además, es de los últimos momentos del Bronce Final y por tanto de un contexto cultural diferente al de la mayoría de las piezas estudiadas. Los objetos verdaderamente plomados son pocos $(8,14 \%$ del total) y no parece haber ningún patrón coherente por familias, cronología y yacimientos. Por este motivo pensamos que el porcentaje de plomo de los metales del Naviforme II y III no escapa de lo que es común en su entorno mediterráneo (Rovira 1995: 56) y seguramente no responde a ninguna característica tecnológica o cultural indígena. En todo caso se podría plantear que en algunas ocasiones, pocas, el plomo se utilizaría para producir algunos bronces ternarios.

\section{TECNOLOGÍA DE MANUFACTURA}

En referencia al trabajo del metal no podemos establecer una comparación entre fases ya que de la primera se han realizado 13 metalografías (sobre punzones y cuchillos) y del segundo sólo una.

En la primera fase se han detectado dos formas de trabajar las piezas. La primera es la cadena de fundición, trabajo en frío y recocido final; la segunda, presenta la fundición, seguida del trabajo en frío, recocido y una última aplicación del trabajo en frío. Otro dato relevante es que no parece que exista un gran dominio de la técnica de fundición: son muy comunes las burbujas de gas debidas a un deficiente enfriamiento de la colada y microgrietas por tensiones durante el enfriamiento o en el trabajo posterior. La tecnología de manufactura sigue un patrón similar a los territorios cercanos (Rovira 2003: 167). Ello reafirma, junto a lo ya documentado en las composiciones, la poca especialización del trabajo.

La única metalografía del Naviforme II y III es una fundición sin trabajo posterior. La información tecnológica en este período debe buscarse por otras vías. Por un lado existe una clara evi- 
dencia de una estandarización y de una mayor producción. También por primera vez se localizan moldes en el registro arqueológico: en el Calcolítico y Naviforme I no se encuentra ninguno y en el segundo 18. Todo ello debe relacionarse también con los lingotes, muy presentes y que reafirman los cambios entre ambos períodos.

La mejora en la calidad del trabajo del metal se refleja en la adopción de nuevas técnicas complejas, como la cera perdida y el sobremoldeo. La primera se constata en al menos dos familias tipológicas diferentes, los pectorales y las agujas. Los primeros presentan las varillas centrales vacías y éstas sólo se pueden haber fabricado con moldes de cera (Rovira 1988). Las agujas también tienen la cabeza hueca y en el interior de una de Son Matge, aún se pueden encontrar restos de arcilla de los moldes. El sobremoldeo se habría utilizado para embutir las varillas de los pectorales dentro de los estuches triangulares que sirven para rematar la pieza (Rovira 1995). En la actualidad aún está por demostrar con seguridad que estas piezas sean de producción autóctona, como sugiere el hecho de que no se encuentren paralelos en ningún lugar fuera de las Islas.

\section{CONCLUSIONES}

Parece claro que, a nivel tecnológico, las diferencias entre uno y otro período son numerosas. El análisis elemental, las metalografías y las demás evidencias de trabajo artesanal en el Calcolítico y Naviforme I, demuestran que la metalurgia de esta época es muy diferente de la posterior. En primer lugar destaca la presencia mayoritaria de cobre frente al bronce (Fig. 1). Otro aspecto técnico relevante, que se observa en las metalografías de esta primera etapa, es la existencia de microgrietas y burbujas de gas en muchas de las piezas, aunque en estos momentos no pueda determinarse el motivo de su formación. También se aprecia una gran heterogeneidad en los porcentajes de estaño de los bronces. Estandarización, por tanto, no es la palabra que mejor describe a estas aleaciones. El motivo puede deberse a la forma de alear el cobre con el estaño mediante co-reducción de minerales, o también al posible reciclado de los objetos. Todo ello sin mencionar la poca variedad formal de los objetos manufacturados.
En las siguientes etapas del Naviforme, en cambio, todo parece sufrir una transformación. Ésta seguramente no fue radical, pero si bastante rápida. Las piezas más antiguas ya son claramente diferentes de las del período anterior. Las lanzas con espigón o las dagas están más elaboradas y presentan un interés en la novedad tanto técnica como tipológica. Las familias (3), que hasta entonces tenían sus referentes en la Península Ibérica, pasan a relacionarse con otros materiales mediterráneos, en concreto en Cerdeña, Sicilia e Italia Continental. A la vez las nuevas formas aumentan exponencialmente: machetes, espadas, lanzas de diferentes tipos, hachas y otras más. La aleación con estaño, ahora ya sí claramente mayoritaria, se estandariza y cuando varía el porcentaje de estaño entre las diferentes familias, parece obedecer a una clara intencionalidad. Incluso las técnicas artesanales experimentan transformaciones destacadas. Los lingotes se hacen comunes, los moldes son abundantes y posiblemente se introducen técnicas avanzadas como la fabricación de piezas a la cera perdida y sobremoldeo. Se puede plantear que surge la figura del metalúrgico, aunque éste posiblemente lo fuese sólo a tiempo parcial.

Resulta imprescindible comentar otros cambios en el registro arqueológico que sirven para reafirmar lo anteriormente comentado. La metalurgia en la primera fase es, en términos cuantitativos, una actividad marginal, tanto en los poblados calcolíticos, como en los de las primeras navetas. La arqueología por ahora no puede contestar a la pregunta de cuanto metal se utilizó en cada momento. Pero si queda claro, que su deposición cambió según la etapa. En el Calcolítico y Naviforme I se ha documentado un total de $2 \mathrm{~kg}$, en cambio en el Naviforme II y III se alcanzan más de $53 \mathrm{~kg}$. Estas cantidades reflejan cambios no sólo de volumen de producción, sino también en la concepción y forma de entender la función y uso del metal.

Pero lo antes comentado no responde a la pregunta de qué significa la metalurgia y los objetos que de ella se derivan. En la mayoría de las ocasiones los investigadores conciben los metales como una evidencia arqueológica de la jerarquización social, independientemente de que los consideren o no su causa. Por este motivo se pre-

(3) En este trabajo se considera familia tipológica como: Categoría taxonómica situada entre el género y el orden. 
suponen unas elites que controlarían la producción, la propiedad y el uso de los objetos de metal, aunque éstos fuesen pocos en número y su impacto económico escaso (Simón 1994: 349; Rodríguez 2005: 181; Rodríguez 2008: 261).

Pero la respuesta no tiene por que ser siempre ésta. Cuando se introduce la metalurgia en las Islas Baleares las sociedades que la reciben, sean las más iniciales del Calcolítico o posteriormente las del Naviforme I, no presentan diferenciaciones sociales destacadas. Con ello no negamos existiesen, pero no se reflejan de forma evidente en el registro. Los enterramientos no se individualizan, las casas siguen unos patrones unitarios y comunes y, posiblemente, la gestión del ganado y de la agricultura eran comunales (Salvà y Hernández 2008; Fornes et al. 2008; Salvà y Javaloyas e.p.). Por tanto si todo el registro habla de unas sociedades poco jerarquizadas. ¿Por qué los metales tendrían que marcar diferencias sociales?

La explicación de la adopción de esta nueva técnica en las Baleares debe buscarse por otros caminos. Como se observa en la figura 7 , un $95 \%$ de los objetos del primer período se encuentran en necrópolis y por ello deben interpretarse como un fenómeno ligado a la muerte. Otra perspectiva diferente a la explicación jerárquica, podría relacionarse con la idea de que lo verdaderamente importante, no era tanto el uso concreto que se diese a cada uno de los objetos, si no el hecho mismo de que estos fuesen de metal y no de otra materia. Según algunos autores, el metal permite la producción de objetos con una forma clara, a partir de un sólido que se convierte en un líquido y posteriormente vuelve a ser sólido. Este proceso en el pasado, incluso en uno no tan lejano

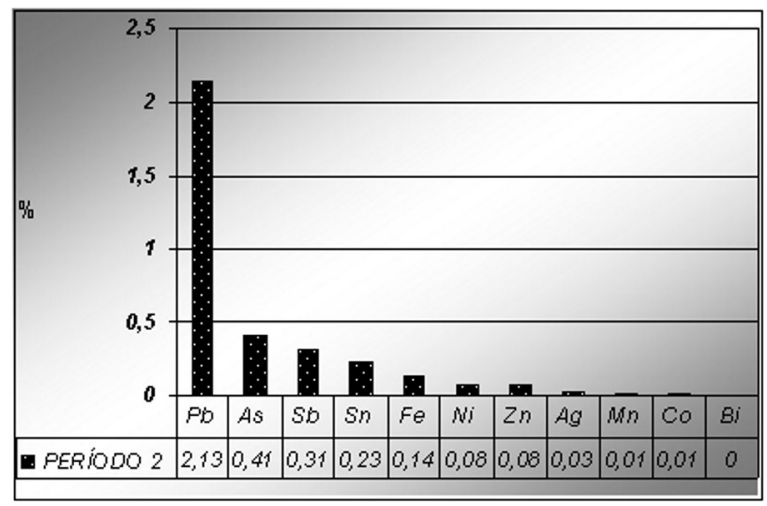

Fig. 7. Medias de elementos minoritarios del 2. ${ }^{\circ}$ período en $\%$ en peso. (recordemos la alquimia en la Edad Media), era considerado mágico. Lo que se obtiene cuando se tiene o se utiliza un metal, es su propia capacidad de transformación. Por tanto, este sería un símbolo de que los muertos pueden cambiar y adquirir una nueva consistencia, entidad o vida. El metal en resumen sería una evidencia de la gestación y la renovación de la vida (Eliade 1956; Hoffman 1995).

Si el metal realmente tuviese esa función, se explicaría por qué en el primer período hay tantos objetos en las tumbas (un total de 339) y también por qué importa tan poco si están o no tecnológicamente bien hechos. Lo que interesa entonces no es tener unos punzones perfectos o unos cuchillos eficientes, lo que es relevante, es que éstos se transforman. Con ello lo que se pretendía demostrar es la capacidad de los humanos de influir en otros mundos y dimensiones, sin excluir que los punzones se claven o que los cuchillos corten, pero éste no sería su primer objetivo, ni su primer sentido.

En el Naviforme II y III este mundo y su concepción de la metalurgia, seguramente cambió, sin desaparecer por completo. Las transformaciones se advierten en la tecnología como se ha visto en las páginas anteriores. Pero también en los lugares de deposición (Fig. 8) y en la extraordinaria diversificación en las categorías y familias (Fig. 9). Aunque éste no es el lugar para explicar cuáles fueron los procesos y cambios experimentados por las sociedades de los períodos finales del Naviforme y sus razones.

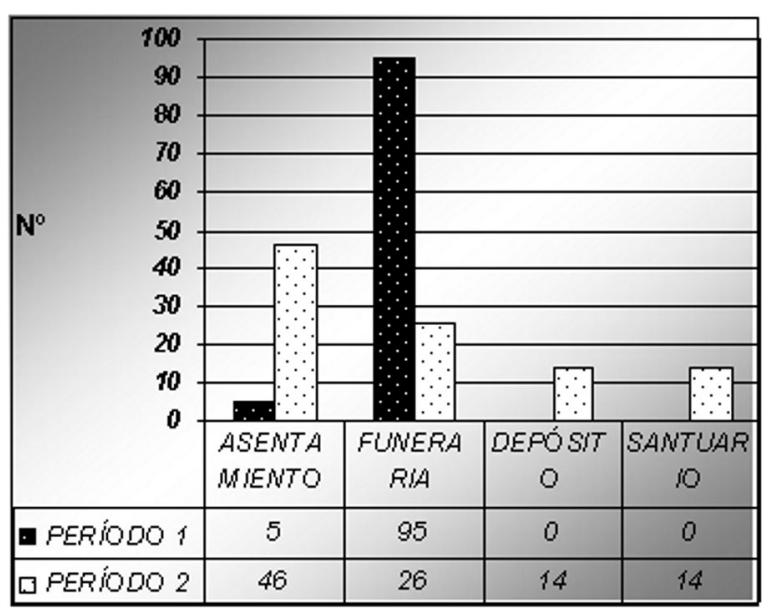

Fig. 8. Función de los yacimientos por período en frecuencias absolutas. 


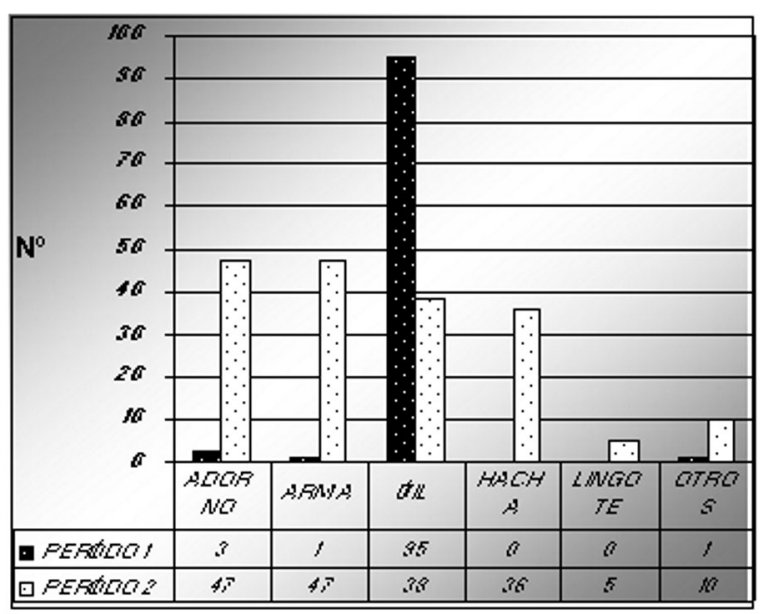

Fig. 9. Categorías por período en frecuencias absolutas.

Finalmente, quiero hacer constar que este artículo no hubiese sido posible sin la guía desde el primer momento del Dr. Salvador Rovira Llorens, al cual no sólo le debo el tener alguna noción de arqueometalurgia, si no también el poder tener un amigo más.

\section{BIBLIOGRAFÍA}

Alcalde, G.; Molist, M.; Montero, I.; Planagumà, Ll. y Toledo, A. 1998: "Producciones metalúrgicas en el Nordeste de la Península Ibérica durante el III milenio cal. a.C.: el taller de la Bruma del Serrat del Pont (Tortellà, Girona)". Trabajos de Prehistoria 55 (1): 81-100.

Alcover; J.A.; Trias, M. y Rovira, S. 2007: "Noves balmes metal·lúrgiques a les muntanyes d'Escorca $\mathrm{i}$ de Pollença”. Endins 31: 161-178.

Calvo, M. y Guerrero, V.M. 2002: Los inicios de la metalurgia en Baleares. El Calcolítico (c. 25001700 cal. BC. El Tall. Palma de Mallorca.

Delibes de Castro, G. y Fernández-Miranda, M. 1988: Armas y utensilios de bronce en la Prehistoria de las Islas Baleares. Studia Archaeologica 78. Universidad de Valladolid. Valladolid.

Delibes, G.; Fernández-Miranda, M.; Fernández-Posse, M.D.; Martín, C.; Rovira, S. y Sanz, M. 1989: "Almizaraque (Almería): Minería y metalurgia calcolíticas en el Sureste de la Península Ibérica”. En C. Domergue (coord.): Minería y Metalúrgia de las Antiguas Civilizaciones mediterráneas y Europeas (I). Ministerio de Cultura. Madrid: 81-96.

Eliade, M. 1974: Herreros y alquimista. Antropología. Alianza Editorial. Madrid.
Fornés J.; Mates F.; Servera G.; Javaloyas D.; Belenguer C.; Oliver, L. y Salvà, B. 2009: "Más que una casa. Los navetiformes en el Bronce Balear". En L'espai domèstic i l'organització de la societat a la protohistòria de la Mediterrània occidental (Ier mil-leni aC), IV reunió internacional d'arqueologia de Calafell: 325-332. Calafell.

Gual, J.M. 1993: Figures de bronze a la prehistòria de Mallorca. Govern Balear. Conselleria de Cultura, Educació i Esports. Palma.

Guerrero, V.M.; Calvo, M. y Coll, J. 2003: “El dolmen de s'Aigua Dolça (Colónia de Sant Pere, Mallorca)". Col-lecció la Deixa, 5. Palma de Mallorca.

Hoffman, C.R. 1991: "The metals of Son Matge, Mallorca, Spain. Technology as cultural activity and behaviour". En W.H. Waldren, J. Enseyat y R. Kennard (eds.): IInd Deya Conference of Prehistory. Archaeological Techniques, Technology and Theory. BAR International Series 574, Oxford, British Archaeological Reports. Oxford: 169-187.

Hoffman, C.R. 1995: "The Making of Material Culture. The Roles of Metal Technology in Late Prehistoric Iberia". En K.T. Lillios (ed.): The Origins of Complex Societies in Late Prehistoric Iberia. Archeological Series 8, Michigan, International Monographs in Prehistory. Michigan: 20-31.

Llull, B.; Perelló, L. y Salvà, B. e.p.: "Nuevas aportaciones para el estudio de la explotación de cobre durante la Prehistoria de las Islas Baleares". En $V$ Simposio Internacional Minería y metalurgia históricas en el Suroeste Europeo (León 2008).

Montero, I. 1994: El Origen de la Metalurgia en el Sureste Peninsular. Instituto de Estudios Almerienses. Almería.

Montero, I.; Gornés, S.; Nicolás, J. de y Gual, J. 2005: "Aproximación a la metalurgia prehistórica de Menorca entre el 2000 y el 650 cal a.C.”. En Mayurqa 30: 289-306.

Perelló, L.; Llull, B. y Salvà, B. (2010): “El coure balear: explotació a la Prehistòria?”. En II Jornades d'Arqueologia de les Illes Balears 2007, 16 i 17 de novembre (Felanitx). Mayurqa 32: 208-225.

Ramis, D.; Hauptmann, A. y Coll, J. 2005a: "Réduction du minerai de cuivre dans la préhistoire de Majorque". En P. Ambert, y J. Vaquer (eds.): La première métallurgie en France et dans les pays limitrophes. Actes du colloque international, Carcassonne, 28-30 de septembre 2002. Memoires Societé Préhistorique Française 37: 217-224.

Ramis, D.; Trias, M.; Hauptmann, A. y Alcover, J.A. 2005b: "Metal·lúrgia prehistòrica del coure a les muntanyes d'Escorca-Pollença (Mallorca)". Endins 27: 19-46. Palma.

Rodríguez, M.J. 2005: Metalurgia y metalúrgicos en el Valle del Ebro (c. 2900-1500 cal. a.C.). Bibliotheca Archaeologica Hispana 24. Madrid. 
Rodríguez, M. 2008: La investigación de la actividad metalúrgica durante el III milenio A.N.E. en el Suroeste de la Península Ibérica. La arqueometalurgia y la aplicación de análisis metalográficos y composiciones en el estudio de la producción de objetos de metal. BAR Internacional Series 1769. Oxford University Press. Oxford.

Rosselló, G. 1974: "Los ajuares metálicos mallorquines como elemento cronológico". En VI Symposium de Arqueología Peninsular. Barcelona, 1974: 115-127. Barcelona.

Rosselló, G. 1987: "Metalurgia en el Pretalayótico Final de Mallorca". Archivo de Prehistoria Levantina. Homenaje a D. Domingo Fletcher Valls XVII-I: 147-155.

Rovira, S. 1998: "Estudio arqueometalúrgico de algunos bronces prehistóricos de las Islas Baleares". En G. Delibes de Castro y M. Fernández-Miranda: Armas y utensilios de bronce en la Prehistoria de las Islas Baleares, Studia Archaeologica 70. Valladolid: 137-167.

Rovira, S. 1991: "Metalurgia talayótica reciente: nuevas aportaciones". Trabajos de Prehistoria 48: 51-74.

Rovira, S. 1995: "Estudio arqueometalúrgico del depósito de la Ría de Huelva. En M. Ruiz-Gálvez (coord.): Ritos de paso y puntos de paso la Ría de Huelva en el mundo del Bronce Final Europeo. Complutum-Extra 5: 33-58. Madrid.

Rovira, S. 2002: "Vasijas cerámicas para reducir minerales de cobre en la península Ibérica y en la Francia Meridional". Trabajos de Prehistoria 59: 89-105.

Rovira, S. 2003: "Els objectes de metal del sepulcre megalític". En V.M. Guerrero; M. Calvo y J. Coll (coords.): El dolmen de s'Aigua Dolça (Colónia de Sant Pere, Mallorca). Col-lecció la Deixa, 5. Palma de Mallorca: 140-145.
Rovira, S. 2004: “Tecnología metalúrgica y cambio cultural en la Prehistoria de la Península Ibérica". Norba. Revista de Historia: 17: 9-40.

Salvà, B. y Calvo, M. 2007: "Noves contribucions a l'estudi del Coval d'en Pep Rave". En I Jornades d'Estudis Locals a Sóller. Sóller, 2007: 113-126.

Salvà, B. y Hernández, J. 2009: "Los espacios domésticos en las Islas Baleares durante las edades del Bronce y el Hierro. De la cultura naviforme a la talayótica". En L'espai domèstic i l'organització de la societat a la protohistòria de la Mediterrània occidental (Ier mil-leni a.C.), IV reunió internacional d'arqueologia de Calafell: 301-325. Calafell.

Salvà, B. y Javaloyas, D. e.p.: “¿Las islas del fin del mundo? Las comunidades baleáricas y los contactos interculturales durante el Bronce Medio y Final (1400-850 a.C.)". En Iié Colloque International. 15-18 septembre 2005. Les lingotes "Peau de Boeuf" et la navigation en Mediterranee Centrale (Mariana, Córcega).

Salvà, B.; Llull, B.; Perelló, L. y Rovira, S. e.p.: "Aproximación a la metalurgia prehistórica de las Baleares: estudio analítico de minerales cupríferos de Menorca". En VIII Congreso Ibérico de Arqueometría (Teruel, 19 a 21 de octubre de 2009).

Simón, J.L. 1998: La metalurgia prehistórica valenciana. Servicio de Investigación Prehistórica. Série de Trabajos vários 93. Valencia.

Waldren, W. 1979: "A Beaker Workshop area in the rock shelter of Son Matge, Mallorca". World Archaeology 11 (1): 43-67.

Waldren, W. 1982: Balearic Prehistoric Ecology and Culture. En British Archaeological Reports, International Series 149, Oxford. Oxford University Press. Oxford. 